\title{
The employment information needs of people with intellectual disabilities
}

by

\section{Andrew Henry}

Submitted to the School of Information Management,

Victoria University of Wellington

in partial fulfilment of the requirements for the degree of

Master of Information Studies

\section{December 2012}




\section{Contents}

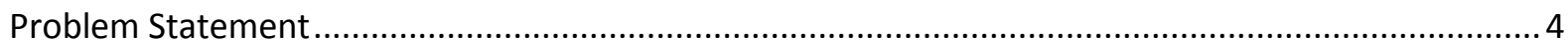

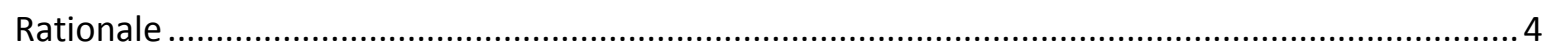

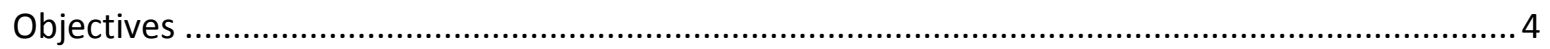

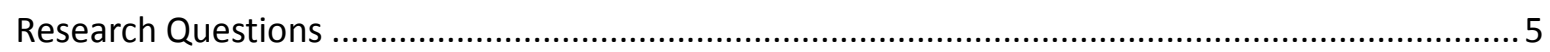

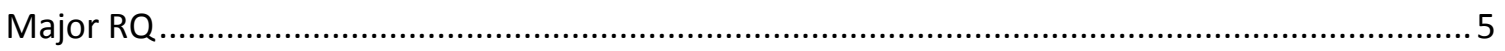

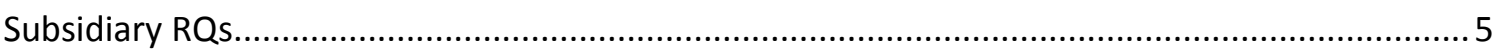

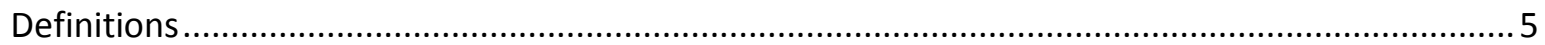

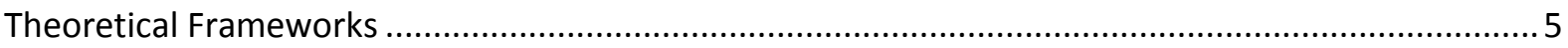

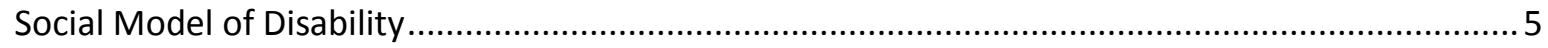

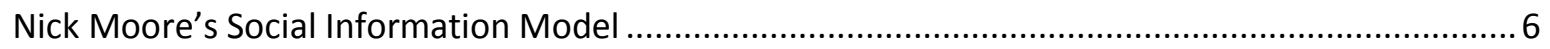

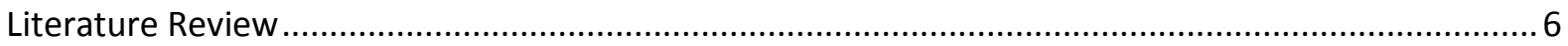

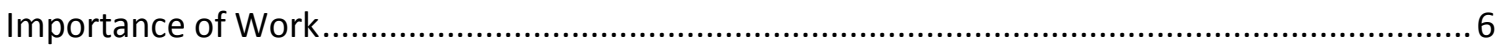

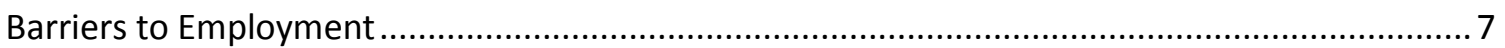

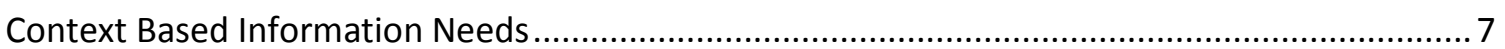

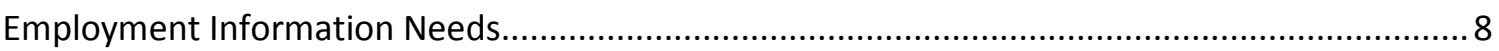

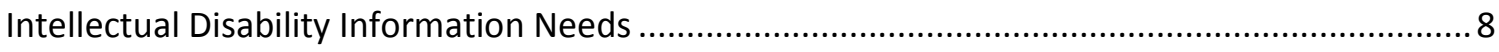

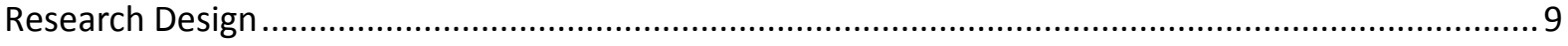

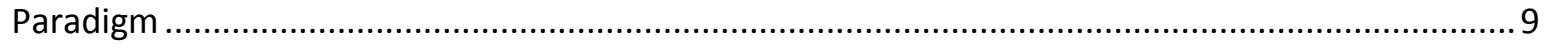

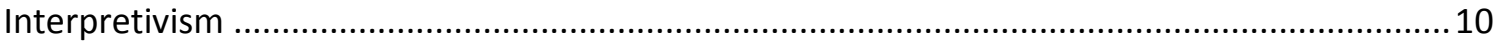

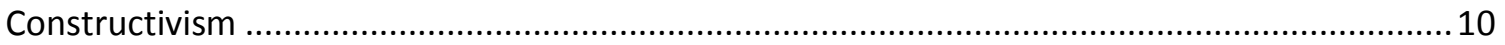

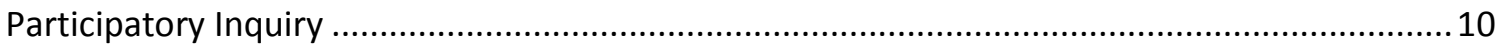

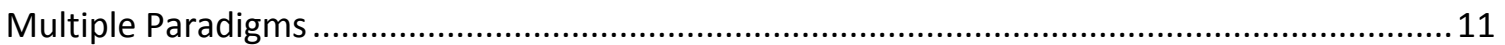

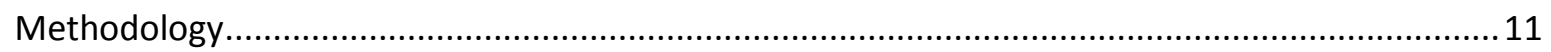

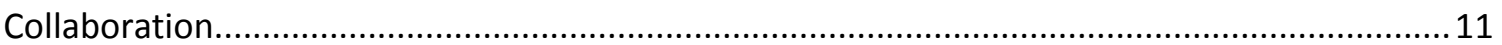

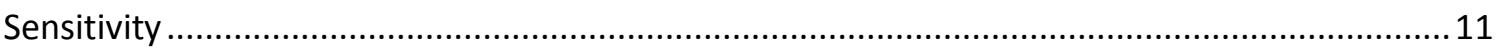

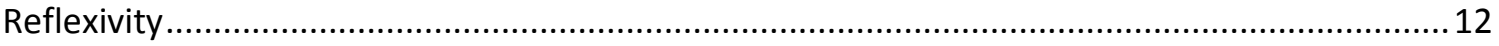

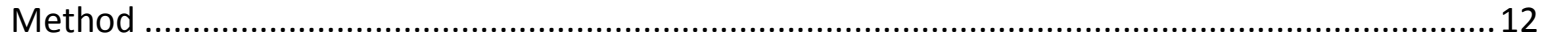

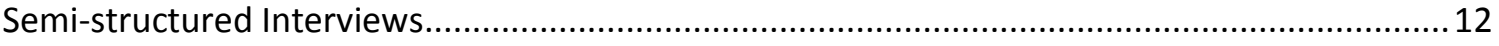

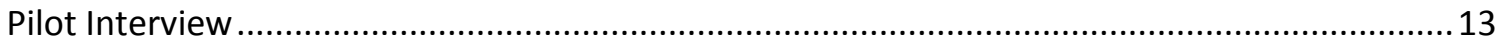

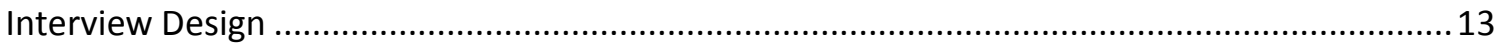

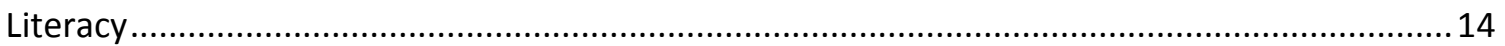

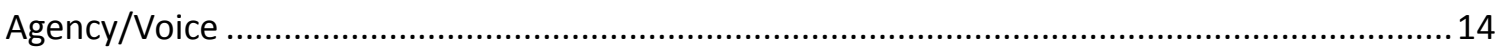

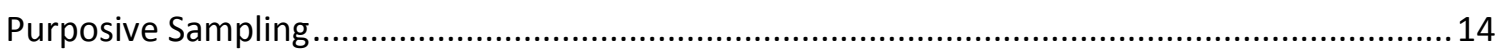




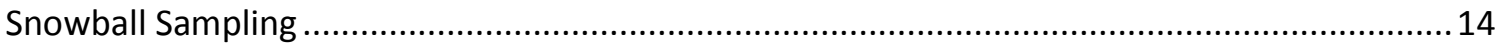

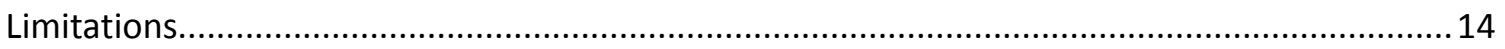

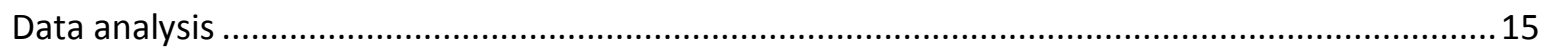

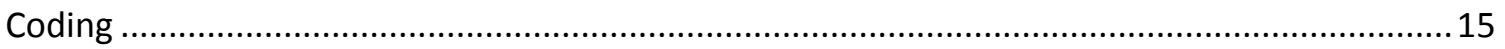

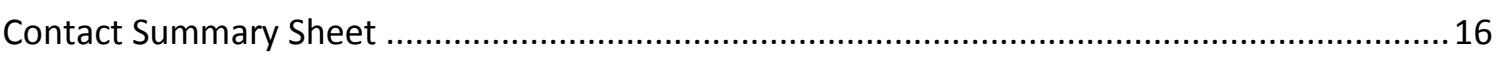

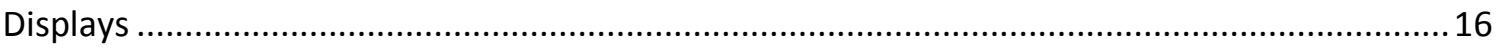

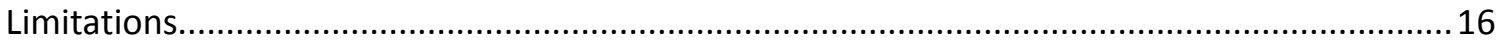

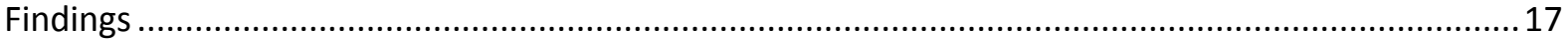

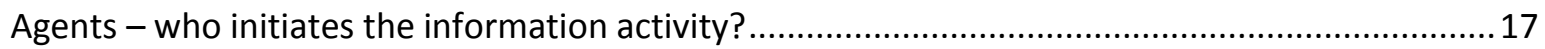

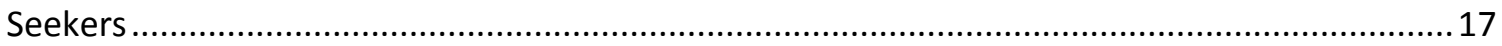

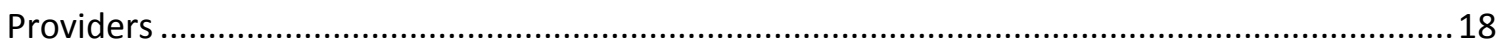

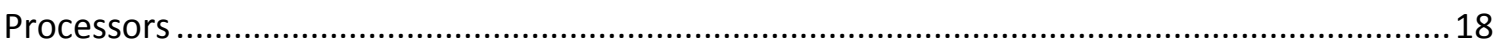

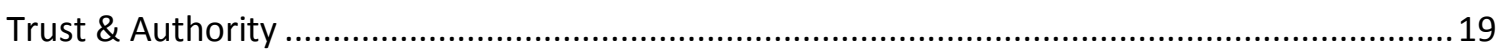

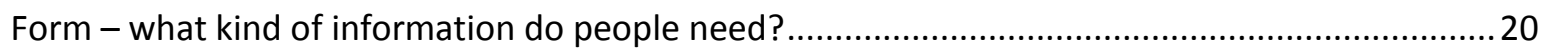

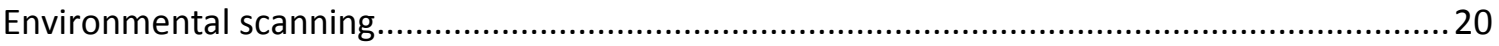

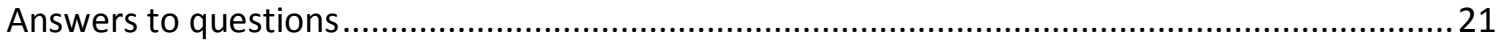

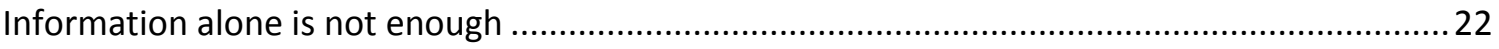

Mechanisms - which mechanisms can be used to meet information needs? .................................23

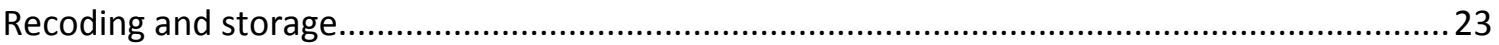

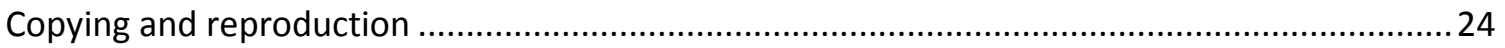

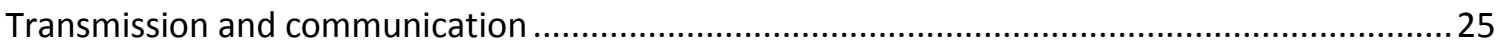

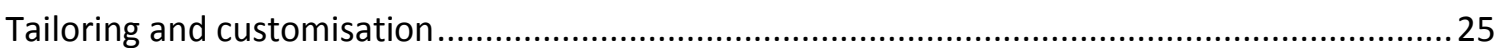

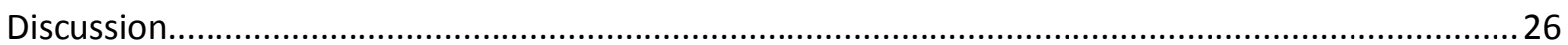

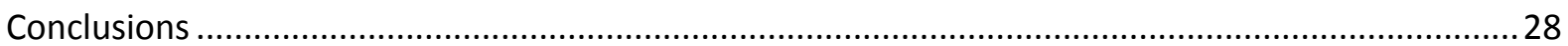

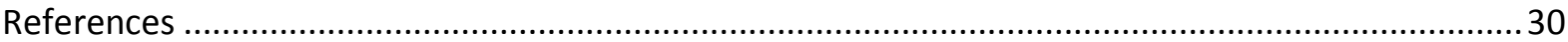

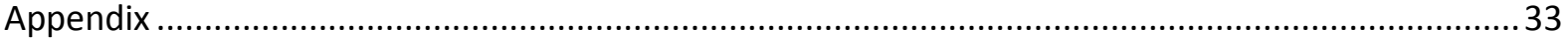

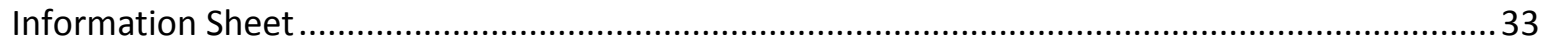




\section{Problem Statement}

\section{Rationale}

New Zealand Human Rights Commission (2011, p.1) states that getting a job is one of the most significant challenges facing disabled people in New Zealand and emphasises that the fundamental inequalities faced by disabled people in employment need to be addressed. This is further exacerbated in the case of People With Intellectual Disabilities (PWID), as noted by Jameson (2005, p.9) in a literature review of the topic, which cites a 2005 survey done by the Equal Employment Opportunity Trust which states that PWID are more likely than people with other impairments not to be in paid work. A report based on the 2001 Disability Survey (Ministry of Health, 2004) found that $51 \%$ of PWID are not in the labour force and, due to changes in legislation (New Zealand Parliament, 2007), this figure is likely to have risen in the intervening time.

Extensive studies have been conducted on the information needs of various different demographic groups (Case, 2007, p.286), however there are few focusing on PWID. Williamson, Schauder and Bow (2000, para.1) conducted a review of the literature and found, "a paucity of studies about the information-seeking behaviour of groups of people with disabilities." This continues to be the case a decade later, and the lack is further exacerbated when specifically focused on PWID and again in the context of employment.

A lack of research is a major justification for selecting a topic of inquiry (Corbin and Strauss, 2008, p.22). Creswell (2007, p.102) says, "The strongest and most scholarly rationale for a study...comes from the scholarly literature: a need exists to add or to fill a gap in the literature or to provide a voice for individuals not heard in the literature." This topic is of significance as there is a gap in the literature and a lack of understanding, so therefore meets Gorman and Clayton's $(2007$, p.69) criteria of intrinsic value for a research problem.

The New Zealand government have clearly stated the desire for research in this area; The New Zealand Disability Strategy, states that objective ten is to, "collect and use relevant information about disabled people and disability issues" (Ministry Of Health, 2001, p.24).

\section{Objectives}

The goal of this research project is to use Moore's (2002) model of social information need to investigate the employment information needs of PWID. The basis for analysis will be three of Moore's (2002) dimensions of social information: agents, mechanisms and form. The agents are the various stakeholders that will be engaged in the process, e.g. PWID, care givers, disability professionals and potential employers. These groups have been identified as sharing common information needs in the context of PWID employment opportunities. The forms of information that are helpful will be investigated as well as the effectiveness of different mechanisms used to meet these information needs. The intention is to gain a holistic understanding of PWIDs employment information needs and ultimately help illuminate potential pathways into work opportunities or Supported Employment (SE). An optimal outcome of this project would be to support Objective four 
of the New Zealand Disability Strategy, which is to provide opportunities in employment and economic development for disabled people (Ministry of Health, 2001, p.17).

\section{Research Questions}

Major RQ

- What are the employment information needs of people with intellectual disabilities?

\section{Subsidiary RQs}

- What mechanisms can be used to meet PWID employment information needs?

- What forms of information are needed to help PWID into employment?

- Which agents initiate the information behaviour?

\section{Definitions}

Intellectual Disability: people who need support or help from people or organisations, or who have been to a special school or received special education because of an intellectual disability or handicap (Statistics New Zealand, 2007).

Social Information: Information that will help people live their daily lives (Moore, 2002, p.297).

Supported Employment: Supported Employment refers to a process in which people traditionally denied career opportunities due to the severity of their disability are hired in jobs and provided long term, on-going support for as long is needed (Dileo and Langton 1993:3, as cited by, Association for Supported Employment in New Zealand, 2011).

\section{Theoretical Frameworks}

The theoretical frameworks for this study are twofold: the Social Model of Disability and Moore's (2002) Model of Social Information Need.

\section{Social Model of Disability}

Mertens (as cited in Creswell, 2007, p.24) explains how disability research has moved from a medical model to the social model. The medical model is outmoded as it "implies there is no hope for social inclusion in the absence of a cure for the impairment (Hammell, 2006, p.58).

The social model of disability views disability as a social construct, in that different impairments only become disabilities when an environment presents barriers or excludes one from performing tasks that others in society could achieve.

The social model of disability, although it has been critiqued, even by Michael Oliver (Oliver, 2009) who initially coined the term, will be used for this project as it is explicitly endorsed by the New Zealand government (Ministry of Health, 2001, p.1). 


\section{Nick Moore's Social Information Model}

Moore's (2002) model of Social Information Need forms the theoretical framework for the research questions and the data analysis as it is a proven model for looking at the information needs of groups with impairments. It has also been applied successfully in different contexts (Okello-Obura et al, 2008; Williamson \& Roberts, 2010).

Moore's model of social information need was, "developed as part of a review of research into the information needs of blind and visually impaired people (Moore, 2002, p.303)." The model was developed to provide a framework for analysis of the information needs of people with visual impairments, thus it will provide a strong basis for investigating the information needs of people with other impairments, specifically PWID. Beverly, Bath and Barber (2007, p.27) concluded that this model was "useful in analysing and interpreting the results" of a study they conducted into information needs of people with visual impairment.

Moore identifies six dimensions of social information which can be used to analyse social information needs: function, clusters, users, form, agents and mechanisms. This project only investigated the latter dimensions, as the first three were implied by the nature of the project. The function is employment; the users are PWID, their care givers, disability professionals and potential employers; while clusters are the life event of finding employment and Maslow's esteem, belonging and self-actualisation needs (Moore, 2002, p.299).

\section{Literature Review}

\section{Importance of Work}

Lysaght, Cobigo \& Hamilton's (2012, p.1) paper presents the results of a scoping review of the research literature on community-based employment for individuals with intellectual disabilities, from 2000 to 2010. They cite the United Nations Universal Declaration of Human Rights - specifically the right to work - as reinforcing the fact that employment is a fundamental need. As noted earlier, employment can help fulfil multiple of Maslow's Hierarchies of need, especially belongingness, esteem and self-actualisation needs. Jameson $(2005$, p.6) notes that," paid work is an important part of our lives. It provides an opportunity to earn an income and also to have social and political status. Work is where many social relationships are formed and social status established."

This is supported by the literature. Lysagyt, Cobigo \& Hamilton (2012, p.1) found that work was an important social involvement and provided a potentially rich venue for social inclusion. In an Australian study Ashman, Suttie \& Bramley (1995, p.113) found very high percentages of participants and their carers held positive views toward their employment circumstance, and confirmed that work has an important part in the lives of PWID. The results of Kober and Eggleton's (2005, p.756) regarding the effects of employment on quality of life for people with ID, "showed that participants placed in open employment reported statistically significant higher quality of life scores."

Furthermore, the results of this study showed that, "people with ID placed in open employment are integrating more with their community and have a greater feeling of social belonging than people 
placed in sheltered employment. Likewise, it is worth noting that open employment appears to be associated with an increased feeling of empowerment/independence (Kober \& Eggleton, 2005, p.759)." These results should be tempered by the fact that open employment is not possible for all people with an ID. Some participants in that study, those described as having a high functional work ability, could choose open employment and as the authors acknowledged that that group seemed to be driving the results.

While completely open employment is not an option for everyone, supported employment is. Lysagyt, Cobigo \& Hamilton's (2012, p.1) review finds that, "Supported employment has become an accepted best practice in employment of persons with intellectual and other disabilities." Therefore this was thought likely to be the most beneficial type of employment to investigate in this project.

In addition to the positive aspects to employment, the negative effects of unemployment should also be briefly mentioned. Berthoud (2008) used a large scale survey to measure the effect of disability on employment. He states that, "Economic disadvantage is an increasingly important component of the social position of disabled people in Europe (Barnes and Mercer, 2005a, as cited in Berthoud, 2008, p.129) and North America (Rupp and Stapleton, 199, as cited in Berthoud, 2008, p.1298) and shows that this can in part be attributed to his findings that people with disabilities are less likely to find employment than those who do not identify as having a disability. The most recent survey on disability and the labour market showed this is the case in New Zealand as well (Statistics New Zealand, 2008).

\section{Barriers to Employment}

Jameson (2005) and Berthoud (2008) both found that employment rates are influenced by the type of impairments that people experience, and an EEO Trust survey (2005, as cited by Jameson, 2005, p.9) found that PWID are more likely to not be in paid work.

PWD are also less likely to be in employment than those without disabilities because they face numerous barriers to find work. Berthoud's $(2008$, p.143) research showed that in the group he studied the chances for PWD to be in employment are 40 percentages points lower compared to non-disabled people with similar family and economic characteristics.

The literature identifies many barriers that PWID face in relation to employment. These range from macro-economic factors, such as the unemployment rate, to more specific reasons such as the policies of agencies working with PWID (Ashman, Suttie \& Bramley, 1995, p.111).

Jameson's (2005, p.12-15) comprehensive review finds that barriers include: access to education and training, access to support, lack of policy support and, importantly, a lack of awareness of the funding and workplace disability support available to employers. Therefore a better understanding of employment information needs could potentially reduce the effect of the latter barrier.

\section{Context Based Information Needs}

Dervin (1999, p.737) commented that, "in... the genre of research focusing on information needs...there are so many emerging perspectives that it is difficult to find coherence." However there is a convergence amongst theorists on the fact that information needs are contextual, and user-centred models are the most effective for investigating them. 
Harland \& Bath (2008) investigated two models of information behaviour in relation to the carers of people with dementia and found that user-centred approaches were better able to recognise the unique needs of individuals than systems-based models. They also concluded that user-centred models could be useful in developing a better understanding of the information behaviours of carers of people with dementia.

Moore's (2002) model describes information needs as active, changeable, and that fulfilment of them is essential for social inclusion. His model also incorporates Case's $(2007$, p.328) point that in real life there are not always gaps or uncertainties that drive people to information seeking. To play roles in society information is needed. This idea is similar to Dervin's $(2005, p .79)$ idea of life circumstances and Tester's (as cited by, Moore, 2003, p.297) claim that for different life events different information is needed. Thus context is established.

Fisher and Julien (in Cronin 2008, ch.7 p.4) remark upon this focus on context in the research literature has been criticized for its lack of both generalizability and theory building. She goes on to say however, that such studies often have local relevance and practical outcomes for improving information delivery systems. Thus, a context based information model was deemed most appropriate for this study, as these are the ideal outcomes from it.

\section{Employment Information Needs}

Marcella and Baxter (1999, as cited in, Webber and Zhu, 2007, p.224) in a UK-wide survey (distributed mainly through public libraries and Citizens Advice Bureaux) found that one of the top six information needs of citizens was information about work.

Webber and Zhu (2007, p.225) cite several older studies of students which show that employment information needs are often fulfilled by informal sources and that people (family, guidance councillors and friends) are important sources of information. Webber and Zhu's (2007) findings supported these older studies and reinforced that affective issues and personal connections are influential when searching for employment information.

In addition to a specific life situation, context based information needs can also focus on groups, like PWID. However PWID information needs are not well covered in the literature, let alone the employment information needs of this group, and there has been a call for more research (Jameson, 2005, p.6).

\section{Intellectual Disability Information Needs}

Koulikourdi $(2008$, p.206) says that there is inadequate knowledge of the information needs of PWD. This is also the case for ID. The lack of research into the information needs of PWID is a serious gap when taken into account the amount of research done on the information needs and behaviour in other demographics (Case, 2002, p.258) and when compared to groups of a similar size (AndreBarron, Strydom \& Hassiotis, 2008).

One of the few studies on the information needs of PWID, by Diana Chike (2006) found evidence that supported the assertion that information needs are changing and contextual. Aveno (1987) undertook a sizeable study of leisure activities of PWID. Although not specifically on information 
needs, an interesting point to note is that watching television and listening to the radio, were ranked top of the list, whereas visiting a library is $16^{\text {th }}$ on the list of 20 activities. An issue connected to this which arose out of Holmes' (2008) research was that PWID were dismissive of the library as an information source as they could not read. This seems to follow Chatman's (1991) findings that the mass media is the most common way to fulfil an information need, conscious or not. Moore's (2002) model is useful as it takes this into account when analysing forms of information and places importance on environmental scanning and passive absorption of information (Williamson \& Roberts, 2010, p.283).

PWID rely extensively on care givers for information. Cooper \& Urquhart's (2005, p.114) study concludes that, "clients now appear to expect home-care workers to act as information gatekeepers." This is an important fact as information needs should be investigated contextually, as they actually occur in the user's everyday lives and not from an idealised point of view (Williams, Bunning \& Kennedy, 2006). This means including care givers when analysing the information needs of PWID will potentially help yield richer data.

One study that employed this methodology was Nind and Seale (2009), which studied concepts of access for people with learning difficulties, a group closely connected to group to PWID. Their research involved seminars, "involving people with learning difficulties and their support workers, researchers and professionals." (Nind \& Seale 2009, p. 275) The most interesting point to arise from this piece of research was that access to information and understanding preoccupied researchers and the professionals more than the people with learning difficulties. This underscores the importance of a qualitative and inclusive method of research into disability issues.

Williams, Bunning and Kennedy (2006) have produced a theoretically sophisticated piece of research on the information needs of PWID, although it is focused on information and communication technologies (ICTs) and does not include any input from people with disabilities. This article provides a good framework, however it is easy to criticise as being about this group and lacking the inclusive imperative of research into disability. One pertinent point that they do make is that, "growing up and living with a learning disability frequently means some form of dependence on the assistance of others to perform those functions and activities that are part of daily life, one of which is to seek and use information (Barron, 2001, as cited in Williams, Bunning \& Kennedy, 2006, p.103)." This reliance on help to function in everyday life was one of Moore's (2002) findings as well in his study on people with visual impairments.

\section{Research Design}

\section{Paradigm}

This research project will be conducted from the under the umbrella heading of interpretivism. As Pickard (2007, p.11) notes, "'Interpretivism' is used as a covering term for a number of approaches to research." Interpretivism can helpfully be called a meta-theory (Dervin, 1999) or a philosophical research tradition (Williamson, 2006). 


\section{Interpretivism}

Blaikie (2010 p.99) states that, "[i]n interpretivism, social reality is regarded as the product of its inhabitants; it is a world that is interpreted by the meanings participants produce and reproduce as a necessary part of their everyday activities together. "

Thus it is larger than being merely a research paradigm and it encompasses many research paradigms. The nature of this project requires the use of two paradigms. Constructivism and participatory inquiry are the two interpretivist approaches that will be used in this research project.

\section{Constructivism}

Pickard (2007 p.12) states that a key feature of interpretivism is that realities are seen as constructed and embedded in context. Many theorists of Information needs and behaviour have advocated the importance of context and the endorsed the idea that humans live in a socially constructed reality (Chatman, 1999; Savolainen, 1995; \& Vakkari, 1994). The idea of a socially constructed reality is one of the major tenets of constructivism and this research paradigm has been influential in information behaviour literature.

Creswell $(2007$, p.19) explains the idea of a socially constructed reality in which individuals develop varied and multiple meaning from their experiences. Importantly, "these subjective meanings are negotiated socially and historically. In other words they are not simply imprinted on individuals but are formed through interaction with others (hence social constructivism)."

Creswell says the goal of research in this paradigm is to, "rely as much as possible on the participants' views of the situation $(2007$, p.21). This is also major characteristic of the other paradigm in which this research project will be conducted in; participatory enquiry.

\section{Participatory Inquiry}

Guba and Lincoln (2005) note that in the evolving paradigms of the social sciences there has been a shift towards social action as the outcome of research, especially in the constructivist and participatory approaches and "that interpretivists see action on research results as a meaningful and important outcome of inquiry processes (Guba and Lincoln, 2005, p.201)." Corbin also states that in conducting social research she, "want[s] to bring about change and make person's lives better (Corbin \& Strauss, 2008, p.11)."

These goals often manifest in 'action' research. Although the preferred term here is 'participatory inquiry' in the literature, the terms action, advocacy and emancipatory research are all used, often interchangeably.

The term participatory inquiry is purposely chosen for this project as it is outside the scope of this project to bring about social change, which is what action and emancipatory research imply. However the collaborative tools and techniques of this paradigm will be employed.

Many disability theorists (Moore, Beazley and Maelzer, 1998; Hammell, 2006; \& Oliver, 2009) have stated that research into disability must fall into the participatory paradigm if it is to be conducted ethically. 


\section{Multiple Paradigms}

The paradigms interpretivism encompasses do share interests and assumptions about knowledge and the world. For instance, "constructivists and participatory/cooperative inquirers take their primary field of interest to be precisely that subjective and intersubjective social knowledge and the active construction and cocreation of such knowledge by human agents that is produced by human consciousness (Guba \& Lincoln, 2005, p.203)."

Denzin \& Lincoln (2005, as cited in Creswell, 2007 p.19) explicitly say that these two paradigms are compatible, and this is reinforced in Guba and Lincoln $(2005$, p. 201) when they say it possible to blend elements from one paradigm to another and that constructivist and participatory inquiry fit comfortably together.

\section{Methodology}

The research paradigms of constructivism, and participatory enquiry, as well as the theoretical frameworks of this project inform a qualitative, collaborative research methodology. Pickard (2007, p. xvi) makes this connection between paradigm and methodology implicit, "A research paradigm does imply a methodology.....interpretivist thinking [is associated] with qualitative research." The nature of the data one wants to obtain also plays a large role in determining technique, in this case contextual data about the social information needs of PWID. Hammell (2006, p.182) has described the beginnings of a disability methodology which primarily addresses the nature of the relationship between researchers and those being researched. The broad features of the qualitative research methodology this project will employ are reflexivity, collaboration and sensitivity.

\section{Collaboration}

Obtaining participants' genuine participation is a key aspect of a collaborative methodology.

Guba and Lincoln (2005, p. 202) describe how research conducted in the paradigms of constructivism and participatory inquiry give prominence to collaboration and this in turn gives voice or agency to the research participants.

Hammell (2006, p.182) states that a disability methodology requires collaboration and should be based on the priorities of disabled people, and that participants are involved in evaluating the research process.

Oliver (1999, p. 115) forcefully makes the point that collaboration must be a feature of the entire disability research process, noting that "If such research is ever to be useful, it must not only faithfully capture the experience of the group being researched, but also be available and accessible for them."

\section{Sensitivity}

Sensitivity is another key feature of the qualitative research methodology this project will use.

Corbin and Strauss $(2008, p .32)$ place sensitivity in contrast to objectivity. Objectivity in quantitative research is a measure of how much the researcher has influenced the study, where the goal is to demonstrate a value-free investigation (Pickard, 2007, p.22). 
Objectivity is impossible in qualitative research, and Guba and Lincoln $(2005$, p.208) have gone so far as to say, "that objectivity is a chimera: a mythological creature that never existed." In addition to this, Stone and Priestley (1996, p.702) contend that objectivity should be surrendered when researching disability using a participatory methodology.

So sensitivity becomes an important methodological tool. Corbin and Strauss $(2008, p .32)$ define sensitivity in qualitative research as requiring the researcher to put themselves into the research, as having insight and as being able to present the views of the participants. These are all important for conducting research into disability issues.

\section{Reflexivity}

To balance sensitivity and collaboration, the other important feature of this qualitative research methodology is reflexivity. Corbin and Strauss $(2008$, p.31) say that reflexivity on the part of the researcher is, "considered essential to the research process".

Guba \& Lincoln (2005, p.210) define reflexivity as the process of reflecting critically on the self as researcher. This entails an awareness of the collaboration and sensitivity aspects of the methodology and how they can affect the research process. This keeps the researchers aware of the extent of their influence on the interaction and how they could influence the data that is collected.

Another important feature of qualitative research methodologies is awareness that it is an iterative process. This is why the research questions are broad, as themes that emerge from the research can then be investigated more fully, and the issues that the participants' voice can be given precedence over hypotheses.

This iterative nature of qualitative research is explained by Corbin and Strauss (2008, p.27), "[t]he interesting aspect of qualitative research is that though a researcher begins a study with a general question, questions arise during the course of the research that are more specific and direct further data collection and analysis." So through reflexivity comes a refinement of the research questions.

Reflexivity is also concerned about researcher presence. Holliday $(2007$, p.163) notes that the presence of the researcher in the research setting is unavoidable and must be treated as a resource. Reflexivity provides a way of dealing with issues arising from the knowledge that much of what the researcher sees is a result of their own presence.

\section{Method}

The method of data collection this project employed was that of semi-structured interviews, with participants identified through purposive and snowball sampling.

\section{Semi-structured Interviews}

Deriving the research questions from the theoretical framework provided a broad guideline for data collection. Semi-structured interviews were chosen to help achieve this goal in providing a flexible, yet defined set of questions. 
The interviews themselves were carried out between late September and late October 2012 and took place primarily in the participant's houses or workplaces and one interview was carried out at the researcher's house. The participants in this study were more than happy to talk, and all had opinions on various aspects of, and issues around disability and employment. Using a pre-existing model for data collection ensured the focus of the interviews remained on the research topic.

As with the entire qualitative research process, reflexivity was important during the data collection (Corbin \& Strauss, 2008, p.31). In practice that meant being aware that the researcher's presence would influence the interview and thus the data gathered.

The interview questions and procedures were refined through reflexivity and iteration throughout the data collection process. That entailed responding to emergent themes and further focusing the subsequent interviews.

\section{Pilot Interview}

A pilot interview was conducted in an informal manner with a PWID who has two part time jobs. The interviewee was known to the researcher, which helped when assessing the veracity of the responses. Moore, Beazley and Maelzer (1998, pp.42-45) describe in details the challenges in inherent in interviewing this population, specifically the tension between asking questions in an inclusive manner and gathering usable data. This was found to be the case in the pilot interview, with the participant answering in the affirmative to contradictory questions. Agility on the part of the researcher is required as to be aware not to prompt answers from the participants and to clarify the questions as well as the answers. Repeating answers back to the participants to ensure they are correct will mitigate this somewhat.

\section{Interview Design}

Pickard (2007, p.180) provides an excellent example of a semi-structured interview about information behaviour. This was adapted to fit the research questions and Moore's dimensions of social information need. Creswell notes the important point that, the interview must be designed with the imperative of producing information that is useful in answering the research questions (Creswell, 2007, p.132). In addition questions not included in the guide may be asked as the interviewer picks up on things that are said by the interviewees (Bryman, p.438). The questions will also be slightly modified before each subsequent interview in light of the responses elicited in previous interviews.

Thus the questions were mainly guided by the study's objectives but were responsive to points and themes that emerged during the data collection process. The questions varied between each participant group, but all interviews consisted of introductory questions (Kvale, 1996, as cited in Bryman, 2009) questions and then moved down through each of the subcategories of Moore's model from which the research objectives were derived. The use of grand tour questions was to make the participants comfortable and get them talking about something know, such as for the employers and SE professionals: "Tell me about your organisation?" For the PWID and the caregiver this introductory question were, "Have you ever looked for information about work before?" and "Do you look for information by yourself?" followed by a question to ask the participants to tell the researcher about these experiences. 
The participants in this study were comfortable giving their thoughts, and all had opinions on various aspects of, and issues around, disability and employment. Using a pre-existing model for data collection ensured the focus of the interviews remained on the research topic.

\section{Literacy}

The interview was the preferred technique, as there could have been issues with literacy for the research participants. Thus all the data was collected verbally. This could also be seen as a limitation of this study as not all PWID are verbal communicators; however it was beyond the scope of this project to include this area of the population in the sample.

\section{Agency/Voice}

Bryman (2008, p.438) emphasizes the flexibility inherent in semi-structured interviews. This was an important factor in choosing semi-structured interviews as the data collection method, for when conducting research in the participatory paradigm and under the social model of disability there must be considerable commitment on the part of the researcher to report the participant's own accounts of the phenomena under study. (Hammell, 2006, p.178)

\section{Purposive Sampling}

Due to the limited population the project involves, the most practical method of gathering data will be from a purposive sample. Creswell (2007) and Miles and Huberman (1994) both advise that purposive sampling is the best approach for qualitative research. As there is no necessity to generalise the findings, there is no need to pay attention to the concept of statistical significance when sampling as one would when undertaking quantitative research. Bryman (2008, p.458) provides a simple definition of purposive sampling: "the researcher selects samples on the basis of wanting to interview people who are relevant to the research question". In the case of this project, the researcher personally knew two of the PWID and the caregiver who were interviewed, whilst one of the employers is a colleague.

\section{Snowball Sampling}

From this initial group of participants known to the researcher, other participants were identified through snowball sampling. Snowball sampling is when "the researcher makes initial contact with a small group of people who are relevant to the research topic and then uses these to establish contact with others (Bryman, 2009, p.184)." Prior to beginning the research this technique was not relied upon, but it proved to be an effective way of finding participants.

The people identified through snowball sampling were the focus group consisting of PWID who were all employed, three supported employment professionals and the employers of a business who employ PWID.

\section{Limitations}

The major limitation with semi-structured interviews is in gathering too much data which then leads to the risk of being unable to use the data that has been gathered. Pickard $(2007, p .181)$ warns of data overload and says this must be factored in to the research design. Using Moore's model as a guide to the research questions as well as the analysis did provide a guide which helped to minimise 
the risks of gathering too much data, and it was also important in keeping the data gathered relevant to the research objectives.

Another limitation of this project is the small size of the sample, as this means that the results will not be able to be generalized. However Dervin (1997, as cited in Pickard, 2007, p. 13) notes that it is impossible to generalise research in the interpretivist tradition. As a generalisation this is not a goal of qualitative research, however it should be seen not as a weakness, but as a characteristic.

Additionally, as Lincoln and Guba (1985, as cited in Beverley, Bath \& Barber, 2007) note, "qualitative research does not aim to be generalisable but attempts to develop findings that can be applied to similar groups." This project will apply some of the methods and techniques of the Beverley, Bath and Barber's (2007) study on the information needs of visually impaired people to PWID.

Only one care giver was interviewed in this project. Beverley, Bath \& Barber (2007 show how important care givers are to visually impaired people when seeking information, thus this could be considered a limitation of the study. However, due to the specific type of information this study was focused on and its qualitative nature (in that it is not attempting to be generalizable) it was thought to be potentially more illuminating to interview a wide range of people involved in PWID information needs and thus the project was approached in that way.

\section{Data analysis}

The interviews lasted between three quarters of an hour to an hour and a half, and were audiorecorded with the participant's written consent. For the PWID who participated in the study the information was given verbally by the researcher together with a care-giver, or in the case of the focus group, their employers. This follows the best practice of obtaining informed consent for research into PWID, in that, "the information provided must be not only relevant but appropriate with respect to the individual's understanding and conceptual abilities (Andre-Barron, Strydom \& Hassiotis, 2008, p.501)." It was decided when going through the Human Ethics Committee process that including care-givers and in the case of the focus group, employers, as information processors for the PWID involved in the study, that this was the best way to ensure informed consent was obtained the research project explained. After this was verbally explained the care-givers and employers co-signed the informed consent sheets with PWID.

At the broadest description, the major data analysis technique this project employed was that of qualitative content analysis. The specific tools used were: a contact summary sheet, coding, and displays. Miles and Huberman (1994, p.12) emphasize the fact that, "qualitative data analysis is a continuous, iterative process." In addition to this, much like the entire qualitative research process, data analysis was conducted in a reflective manner.

\section{Coding}

The initial codes and themes for analysis were determined from Moore's model. These came from the research questions which correlated to the dimensions of social information need that Moore put forward in his model: forms of information, information agents (who initiates the information activity) and mechanisms that can be used to meet information needs. 
The other type of coding that was employed was in-vivo coding, where phrases that were commonly used by the participants determined the additional codes (Miles \& Huberman, 1994, p.61). This was used because giving the participants' voice is essential in disability research and the participatory paradigm.

The other coding categories and interview questions that emerged from what the participants had to say were the importance of personal and affective features on information seeking, and the structural information barriers, or bureaucracy, for the SE professionals and the employers . According to Gorman and Clayton (2007, p.211), “...the coding process is the key to meaningful data analysis."

One of the most important manifestations of the iterative nature of qualitative data analysis was that the validity of findings could be tested on subsequent research participants. In this way data analysis did influence the data collection.

\section{Contact Summary Sheet}

When each interview is finished, a contact summary sheet or an interview overview was completed which helped to identify emergent themes and look for patterns. This was filled out with reference to the notes taken during the interview and from memory. These themes and patterns in turn influenced some of the questions that were asked to subsequent participants and also the coding and framework analysis process.

\section{Displays}

Miles and Huberman (1994, p.11) note that another important qualitative data analysis technique is that of displays. They refer to the use of tables, graphs and matrices. The major display tool I used was the framework analysis matrix, which is essentially a thematic table (Bryman, 2008, p.555). The themes that were used in this tool were the ones identified above and the ones taken from the research objectives.

\section{Limitations}

The major problem with coding is that the context of the data (the words) can be lost as it is fragmented into pieces, however by using direct quotations and having some codes and themes identified prior to data collection by the use of Moore's model this problem can be significantly reduced.

To undertake authentic participatory research the participants should be included in the analysis of the data (Hammell, 2006, p.180). This was thought to potentially be a limitation of this project during its planning stages and it proved to be so as time constraints made this difficult to achieve. However, all participants were given the opportunity to ask questions around the issues that were discussed during the interviews and were encouraged to make contact with the researcher for any clarification.

All participants were told that they would be given copies of the project upon completion and this will be the case when it is returned to the researcher by the University. 


\section{Findings}

\section{Agents - who initiates the information activity?}

The different categories of information agents were taken from Moore's model, but the findings of this study would suggest that all the participant groups acted variously as each kind of agents in different situations. The supported employment agencies in particular seem to have a very complex information world.

\section{Seekers}

Two of the participants WID had never looked for employment information before.

One felt it would be hard to find and was unsure of how to contact potential employers. This participant was also unsure about the availability of jobs, which was an influencing factor on his decision not to go and look.

Another participant got employment information from many different personal sources: a friend, another Service User, a caregiver and from the higher management of his residential facility. This reliance on personal information sources is shown repeatedly in the results of this study and reinforces how important it is.

The caregiver who participated physically went into a local fast food outlet and asked for employment information for a PWID in their care at that time. When asked what they did with this information the caregiver said that they acquired it, but that, "[person] wasn't ready at that time, for work." This example shows that, more than motivation; preparedness to enter the workforce is required in addition to specific information around a job. The results of this study suggest that this fact is well known amongst people dealing with employment issues around PWID, and this is further explored below under Moore's subcategory of 'Information alone is not enough'.

The focus group of PWID were actively engaged with a Supported Employment Agency, who some connected with through their schools. It seems that once the connection has been made both the PWID and the SE case managers approach each other; the relationships are on-going. The focus group participants said that their case managers at the supported employment agency were very helpful in providing information to them.

Both of the employers said that they had no problems in finding employees. This suggests a situation where there is far more demand for supported employment than actual supply.

These employers are unique in the fact that both see themselves as stepping stones for their employees who will move on to other employment or training.

Both SE agencies gather a lot of information around PWID so as to get the best results in job matching. This is a very personalised process, which includes some questions around the impact of the disability on the individual. One of the SE agencies initially asks only a very few personalised questions so as to build trust with their individual clients. Many of these questions are also around more functional issues like medications, allergies, transport and traditional employment questions like the technical abilities of the person. 
One of the SE professionals said that getting updated "history or background" information was hard to obtain, which can be seen as a difficulty because this information is important in beginning the SE process.

One of the SE agencies said that a "primary objective" of theirs is to seek out contacts for training, educational courses and work experience. This is done through actively being out in the community and talking to people.

When looking for potential employers both SE organisations use the strategy of cold calling. When they do get talking to a potential employer, they ask questions of them: one of the SE agencies said that they talk primarily about the employer's business and what gaps they have in their workforce, noting that "You're there to ask them about their business rather than tell them about yours. You'll be looking to see how you can fill the gaps...they'll be telling you about the gaps and what they need". The other SE agency said something similar about when they first talk to potential employers - "It's more about them asking us the questions." Therefore, usually when looking for potential employers the SE agencies in this study act as information seekers and initiate the contact.

\section{Providers}

Both of the employers described a complex information seeking and provision situation after employing PWID, in terms of the benefits that are available, subsidies they can apply for as well as funding they could receive. Both of these employers expressed frustration with the bureaucracy around this area.

The employer with the on-going relationship with the SE agency said that they, "mainly left information provision up to [them]" in terms of the service and experience that this employer provide at their workplace.

Although both of the SE agencies sought out a lot of information from both employers and PWID, they both consider themselves to be primarily on the other side of the equation, noting "We're more information providers than anything else." This includes providing information about the expectations of the service to potential employers and plenty of information around employment and training to PWID and their care-givers.

Both SE agencies said that they get a lot of PWID coming to them through word of mouth, and one said they had many self-referrals. Thus in the case of PWID and the SE agencies it seems that PWID and their care-givers initiate the information activity. A care giver said that the people at the management level of the care facility would initiate contact with the Supported Employment professionals, commenting "That's normally done by the management level, normally the managers make decisions and contact direct with them."

In terms of providing information to PWID who are involved in their service, one of the agencies always provided three options for each PWID they are helping into work.

\section{Processors}

All of the PWID who were participants in this study were helped by their friends, family, caregivers and professional staff with processing employment information: 
"Sam [care-giver] told me about it [a part-time job]."

"Mum can help with contracts"

"My Mum gave it [training course information] to me."

The caregiver said that processing information for PWID was a daily activity and something that was a normal part of their job. In a different context they related explaining travel information to a person in their care, which involved reading some brochures they had found and explaining the contents at the same time. Professional skills combined with personal knowledge are the keys to information transmission as everyone communicates in a different way and intellectual disabilities manifest in different ways.

One of the employers found that the Privacy Act was a barrier to processing information about their employees, as it effectively stopped them from being able to ask what a person's disability was, which could be dangerous in a workplace. Neither of the SE agencies' found this to be a problem nor did the other employer, who said that, "pragmatism was more important." This could suggest that it is not a huge problem around the employment of PWID and perhaps this reinforces the fact that a lot of the work around employing PWID is iterative and inclusive and that relationships are established long before a final job interview.

In addition to PWID's caregivers, the SE agencies both help the PWID involved with their services to explain information of various kinds. The specific types of information mentioned in the interviews were employment contracts, which often need provisions for extra sick leave and support plans for the workplace. They also explain to PWID what they are legally required to disclose to potential employers during the interview and recruitment process, "we school our clients up a lot on 'what are you required to disclose?' ... 'why are they asking you this?'...and avoiding over disclosing really."

\section{Trust \& Authority}

Both of the employers interviewed had similar views on the importance of trust and authority when seeking employment information from an employer's perspective. One said that their experience in this line of work was important and now when looking for new employees they could call their SE agency and say, "we're looking for a [name]", thus effectively describing a skill set of a previous employee that both organisations were familiar with. This employer said they do rely on trustworthy information and this comes from a long working relationship with this SE agency. The other employer said that contacts they had made along the way were important too, "We've had to build that relationship up." This suggests that experience seems to be a big factor when deciding on the veracity of information.

Trust and authority were important features of the information flows for the SE professionals as well, with both agencies that were interviewed remarking that trust and openness were important, and that trust was built through being open and honest with PWID and potential employers.

One way of building trust for one of the SE agencies was the incremental information-gathering from the PWID who use their service. By initially asking only a few questions of them, the SE professional felt that they could build a rapport which was important to the success of their service. An 
alternative method for building and maintaining trust for this agency was through a privacy agreement between them and the PWID who use their service.

Form - what kind of information do people need?

\section{Environmental scanning}

Information absorbed through environmental scanning was an important factor for PWID in their thinking about employment.

For one participant who had never looked for employment information before, a friend's negative experience with a work trial reduced the participant's interest in trying a similar thing, "My mate's first job was doing cars....he only just did it, a one time basis and that was it. He did enjoy it." However nothing came of this experience which discouraged the participant's interest in trying the same type of thing.

For another participant, a rude potential colleague was a discouraging influence, with the participant noting "the woman was very rude to me, so I don't want to work there."

These previous life experiences for these participants in the area of work seem to play a large role when deciding to begin seeking employment information.

The focus group felt that they did not hear very much about employment in their everyday lives, and that they needed to look for it. This finding further suggests the importance of studies in this area.

The caregiver thought an improvement could be made in this area by increasing community engagement, through things like social gatherings and engagement with families. This would perhaps reduce the lack of passive information absorption by this group, which is an issue according to the focus group participants, as mentioned above.

Environmental scanning was essential to the business of one of the employers, from the start of operations through to now. Their business is based on an existing one that they'd heard of operating in Porirua and recently the operator said they'd recently heard, "that WINZ are now focusing their funding on people under twenty-five and that they will require measurable outcomes." This ongoing reliance on environmental scanning suggests how important it is.

Environmental scanning was a very important method for obtaining information for one of the SE agencies. That said that as they were out in the community and talking to people involved in training, as well as employment, it was important to sustain these relationships. This SE agency also considered training and educational and vocational courses as outcomes of their service and as such it was important for them to know what is available for PWID who they work with.

\footnotetext{
“Because we're out there, we sometimes look for voluntary work contacts...We also look for anything in the way of courses or education...anything from literacy to art, craft any of those sorts of courses as well...learning skills, life skills courses...Just for contacts to pass on to others."
} 
The on-going relationships they have with people involved in these areas are important contacts for this kind of information. By contrast the other SE agency said that, apart from one, they do not have many on-going relationships with the employers they contact.

\section{Answers to questions}

The participants with intellectual disabilities all agreed on the main answers to questions they would require around employment information, which was mainly practical information: transport, location and the accessibility of the workplace.

More importantly they all wanted to know to know about the day to day routines in a potential workplace:

"Need to know what it's about."

"What the procedures are."

"You need to know the routines of what to do."

These results are quite understandable in the context of PWID, considering many have no work experience and therefore no previous experiences of a work environment against which to compare a potential future workplace.

The caregiver interviewed had many of the same questions that the PWID interviewed had: the location of a workplace, travel, hours, what kind of support was available at the workplace

One of the employers had very specific questions that they need answered: they "need to know" if a PWID in their workplace has epilepsy as this could be dangerous. Also on the administrative side this employer said they needed to know that the wages they're paying to their employee are not jeopardising the employees existing benefits. On a personal level, the employers need to find out specific characteristics of each employee, "because unless you tap into that person you don't realise what they're capable of." This is both in terms of tasks in the workplace and other training options outside of work.

Both of the SE agencies asked similar types of questions of the PWID who they work with, as well as potential employers. The questions for the PWID are around the individual's aspirations, their history, and from there they would begin the SE process. The questions for the employers were initially focussed on the employer's business and what it's needs are and from there they would ask specific questions around the types of work at their workplace and what kinds of jobs thy did.

Another question PWID had was about the training and support they would receive in a potential workplace, "You still have to have training." The participants with no previous work experience said it was difficult to imagine how they would be supported in the workplace and how training would be provided.

These questions also relate to the next subcategory of Moore's model, that information alone is not enough to trigger an action or answer a question. 


\section{Information alone is not enough}

In addition to these specific questions about employment, the PWID interviewed felt there were other issues that influenced whether action was taken.

These other issues included 'internal' factors such as: motivation, hygiene, CV preparation, interview skills and, perhaps most importantly, the knowledge that they can do the job or that they have the skills and abilities to perform the job.

One member of the focus group expressed concern about applying for jobs as they were aware of their lack of experience, "it's [scary] putting our name out there". Another PWID who was interviewed said they would be worried about taking a job because, "if you make a total cock up, then you're stuffed." These concerns reinforce the issues of two other participants, identified in the previous section, who needed to be comfortable they could do a job before beginning to even look for employment information. This is entirely understandable considering the lack of work experience in this group.

The caregiver emphasised that it was important to know the personalities of the PWID before assessing employment information and also how the nature of that person's disability affected them, "according to their ability, their motivation and how fitting they are to that work."

Both employers made specific mention of the fact that they were aware that more than just information was required in providing a supported employment service. Both employers see their work places as a "grooming ground", "a stepping stone" and a place which is at "the start of work life." Both employers provide a holistic environment which includes training, support and teaching life skills. One of the employers even provides on-going support, including dropping in to see a former employee at their new place of work and "calling in with some muffins or a salad for lunch." This same employer provides assistance in obtaining qualifications for their employees: "my husband keeps a diary for them which they need to get their horticulture qualification."

The awareness of this training role of their workplaces also manifests in one of the employers in observing their employees as they work. They do this so they can gage the employee's skills and see them on a day to day basis, which is valuable information to feedback to the SE agency, noting "We will try and find out what the guys are really interested in, this is only a stepping stone." This can influence future training, learning and employment options and thus provides very important information.

This view of supporting PWID into employment as a holistic work and life skills enterprise is shared by both of the SE agencies that were interviewed, as one of them mentioned above, training and even work experience are outcomes for them. One SE professional said that, "the job is the tip of the iceberg" and that all the work leading up to that is just as important.

Both SE agencies spoke about the importance of job matching. Both used the same phrase when talking about this, that "people are not set up to fail." A good job match is seen as critical to the success of the employment, as this is a personalised, iterative process that can be very lengthy. One of the SE agencies said that it can take up to eight months from the first meeting to finding a workplace. In addition to the concrete information employers provide, one of the SE professionals said that it was important to try and gauge the environment of the workplace, which would be done 
through visiting and talking to employers. An important part of not setting people up to fail is job matching and ensuring they will be placed in a supportive environment, commenting that "it's not just about the skills a person brings to a place, it's about the...environment that they're going to be working in."

\section{Mechanisms - which mechanisms can be used to meet information needs?}

\section{Recoding and storage}

The discussions around printed information conveyed that the PWID felt printed information was sometimes useful. One of the focus groups participants said that through a supported employment agency they had been given list of job websites, "which is helpful". However this participant was concerned about the currency of the information on this list as, "some sites could have crapped out". This reflects the parameters Moore mentioned in his model on this information mechanism.

None of the PWID felt that printed information in the form of a newspaper was important when looking for employment information. This, however, could be due to literacy issues as the caregiver interviewed preferred newspapers when looking for employment information for PWID as the information newspapers contained was current and they felt that the internet could be time consuming, noting that "Newspapers come out every day and every day we get first-hand information and the internet sometimes take time to get what you want."

However, again personal or affective issues could be factor in the prejudice against newspapers as a mechanism for employment information for PWID as, one of the focus group participants said that they, "can tell when looking at job advertisements in the newspaper that they're out of my league."

Printed CVs were not important for either employer; one of them said that, "face value is better". This was agreed by both the SE agencies. One SE professional said that they had, "been asked for a $\mathrm{CV}$ once in eleven years" which further reinforces this point.

One interesting similarity between the employers was they had both been featured in newspaper stories and that had both found this very important. One said that "we've had a lot of publicity in the papers." They both agreed that these stories had increased their exposure and one of the employers said that it led to people interested in their workplace calling the SE agency they have a close relationship with: "Every time there's been an article they get inundated with people, with parents." In one extreme example, one of the employers said that the parents of a PWID moved their child closer to this workplace to increase their chances of securing employment. This anecdotal example suggests the essential nature of this promotion and recognition of workplaces that are capable of providing supported employment for PWID.

The stories mentioned were features on how these employers ran their workplaces; neither employer advertised in the newspaper. One employer is provided with all their employees through a supported agency with whom they have an on-going relationship, and the other uses word of mouth as well as the publicity garnered from the newspaper article. This employer also mentioned that, "being in a small community has increased their exposure."

Both of the SE agencies used business cards and brochures to provide information about their services and how to contact them. One of the SE agencies saw these as merely introductory tools, 
and as a stepping stone to a one on one conversation: "I'm not a great believer in printed information as a way of employers getting, knowing what you do. Everything is only an introduction...stepping stone."

A problem that one SE agency mentioned in relation to recording and storage of information involved looking for information about a PWID who they were working with, when often the printed information about a person could be out-dated.

With reference to newspapers, one of the SE professionals said that when they scan the employment advertisements, that they are primarily looking for a name or a contact with whom they can talk. They discounted the importance of printed information saying that they were, "not a great believer in printed information as a way of employers getting to know what [we] do." Another problem this SE professional found with their organisation's printed information was that it was dense, with many pages, and they did not feel that this was the best way to provide information:

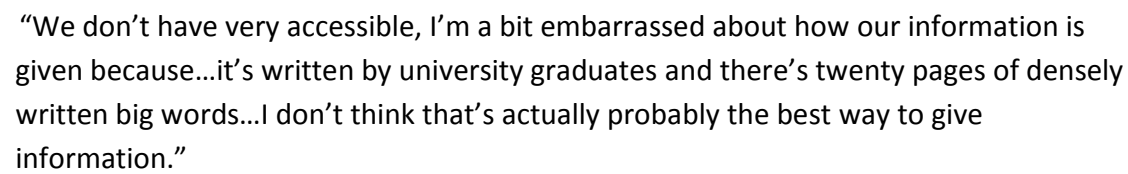

Thus they essentially regard the printed information they use as introductory.

\section{Copying and reproduction}

One of the PWID participants remarked that they thought a DVD explaining supported employment would be beneficial to their preparation for looking for employment information, noting that a DVD about supported employment would be good."

The caregiver thought that it was important for the PWID in his care to have a home internet connection as "it is now a basic thing". In addition, a printer is required so that the information could be printed out and digested by the PWID in their own time or when a caregiver had time to help explain and process the information for them: "bring[ing] the information closer to the Service Users is important."

One of the employers found that funding and grant application was a very labour intensive process and that applying for subsidies involved "a lot of paperwork."

Much like the printed information above, one of the SE agencies did not find digital forms of information very useful for finding potential employers. Their organisation's website was described as "the icing on the cake" and email was not used for contacting potential employers.

One SE agency said that, "online job applications are not effective at all in terms of getting interviews for PWID; " They felt that this was because Human Resources (HR) departments in organisations were too risk averse and a big and real barrier to getting PWID job interviews or even talking to their organisation, "HR says no, no, no...run a template over them. HR is risk averse, the whole industry is." 


\section{Transmission and communication}

Internet access at home for the PWID interviewed varied, although all participants were happy using it to find information. The caregiver interviewed had used the internet to look for employment for PWID, but only on mainstream employment sites, not specific supported employment sites. The caregiver said they "did not feel very comfortable using the internet."

Most of the participants preferred talking in person, either to a potential employer or with a supported employment agency; however one preferred using the telephone and another one preferred using email. This was because the phone is "easy" and for the other participant, "sometimes I'm better at communicating by email." In the majority though, the preference was for face to face conversations as a mechanism for fulfilling employment information needs.

The caregiver also thought that meeting face to face with potential employers together with the PWID in their care was the best means of communication as they thought that it was important that, "they interact and get a feeling for each other."

Both of the employers interviewed reinforced this idea as they both emphasised their preference of meeting people in person. One employer said that, "We'll have them down for a day or two for a trial...they have to be able to work together." The other employer said that, "Quite frankly anybody can write a CV and make themselves sound amazing. We prefer to meet the people in person."

One of the SE agencies was averse to using email as a way of contacting potential employers for anything other than appointments with existing contacts. It was not used for discussions with potential employers as this form of communication was seen as "not for giving information."

Both of the SE agencies prefer to speak to potential employers face to face. This face to face communication is achieved through multiple meetings, regular communication which helps to build the relationships. This is reinforced by the on-going nature of supported employment.

\section{Tailoring and customisation}

The caregiver did note that there could be communication problems when speaking face to face, and felt that it was important for someone who was familiar with the PWID and how they communicated to be there when talking to potential employers or supported employment agencies, "Certain people with a disability have certain disabilities and if you don't know them you can have a communication problem."

When the caregiver looked for employment information for the PWID in their care they used their knowledge of these people's skills and abilities when scanning for potential workplaces. Thus it was personalised and customised before the options were even presented to the PWID or potential employers. This intimate knowledge of the PWID that caregivers work with is an important part of the employment information process for PWID and both SE agencies included care-givers in meetings around individual's employment aspirations and plans.

One concrete manifestation of how a SE agency created tailored or customised information was that for some of the PWID they worked with, they created visual aids, such as picture books to help explain each task the job consisted of: "sometimes we make up little picture books... to help them with visuals." They also broke jobs down into smaller steps, noting "We'll break it [the job] down for 
the Service User because most of the people we work with are not too good at multi-tasking, so we will introduce it first as just a few basic tasks."

PWID preferred going to see potential employers and speaking with them face to face when finding out information about employment. As one participant mentioned, "it's good to see the people you will work with."

The focus group all felt that going to the workplace in person and being shown the job's 'procedures' was the most valuable way of gaining information about it:

"That's when we really found out about it"

"[We] mainly found out about the job when we came here. [Name] showed us through the procedures."

These statements seem to support the idea articulated in the "Answers to questions" subsection, that the lack of experience in work environments for PWID restricts the range of questions that they have for potential employers.

This finding suggests that the lack of experience and confidence felt by PWID is a real barrier to even beginning to search for employment information.

\section{Discussion}

The interviews conducted during this project revealed that most of the PWID participants were not looking for employment information, as they were unconfident about their actual employment prospects. The employers interviewed certainly viewed themselves as providing holistic work and training environments, and the SE agencies both emphasised the iterative nature of their programs, but perhaps this information needs to better communicated to the PWID and their caregivers. Perhaps promoting the notion that a PWID is not merely seeking employment, but that they are starting a journey involving gaining skills, life and work experiences with the aim of attaining employment could reduce the hesitation and make PWID more confident in going to look for employment information. This could potentially become increasingly important as one of the employers said they noted a trend in WINZ targeting funding towards places that provide measurable outcomes. It is very difficult to measure some of the skills and confidence that is gained from being in these employer's workplaces, however one such method could be noting the number of PWID who have been employed there are now working fulltime in other places.

One of the employers interviewed did not believe that the PWID that approached them were aware of the extent of the support available in their workplace. How to make PWID more aware of this is one issue, but perhaps these are exceptional employers and the real issue is finding more workplaces like this. One SE agency certainly thought that identifying which employers were truly open to providing a SE environment (who are not currently involved in SE) was an important piece of work that needed to be done. Instead of the SE agencies initiating the information activity on an ad hoc basis by cold calling potential employers, perhaps a survey could be done to identify employers who were truly interested in exploring SE. 
There is certainly real awareness amongst everyone interviewed that personalising information is crucial to its success in being communicated. The results suggest that this is the case and this is not surprising given the person-centred focus of the disability organisations and professionals involved in the project, and the recognition that ID manifest themselves differently in each individual. This personalisation of information can manifest in SE where things like social behaviours are taken into account when job matching.

Both employers who were interviewed and SE professionals mentioned barriers to getting people into work. They experienced these barriers when looking for specific information, and thus fall under Moore's subsection of forms of information: answers to questions. An employer said that there is an incredible amount of paperwork to do when applying for subsidies. A SE professional said that they find getting exemptions to the minimum wage very difficult. These appear to be structural barriers to intellectual disability employment information, which are there as a result of Government policies. Perhaps considering all the other obstacles to getting PWID into work, and with the explicit encouragement from the New Zealand Disability Strategy, reducing these difficulties in information provision could be considered.

Another structural barrier relating to the forms of information that can help PWID obtaining employment is the nature of the subsidies. In addition to the work entailed in obtaining a subsidy (according to an employer), a SE professional said that their structure is such that it discourages employers and SE agencies to apply for them. Subsidies are set up to provide the employer with extra funds to cover the loss in productivity whilst training up a new employee for up to one year, although this can be extended in the case of ill or disabled people (Department of Labour, 2011). In practice, according to one of the SE professionals, these subsidies disadvantage PWID in the workplace as these employees may never get to one hundred per cent productivity and this discourages employers from going down this avenue. Thus the structures of these subsidies, which are meant to help PWID into employment, in some cases have a converse effect.

All participants mentioned how important it was to meet people and 'get a feeling for each other' when seeking and providing employment information. This suggests that personalised transmission is an essential part of the information needs of PWID. This also suggests that the affective dimensions of information seeking are very important to participants in this study. Moore's model doesn't specifically have a category of analysis for personal experiences in his model, although aspects of this are covered in the 'Environmental Scanning' and Tailoring \& Customisation' subsections.

Another affective factor in determining when PWID search for employment information is their previous experiences and expectations around looking for and successfully finding employment. As the results of this study showed, many participants were nervous about beginning to look for employment information as they had very little previous experience in doing so, and they held reservations about their chances of being successful.

All of the PWID in the focus group had found employment, but nonetheless a few agreed that looking for a job was a scary process. A lack of work experience decreased the confidence of participants, and was exacerbated by their lack of formal qualifications. Writing-centred qualifications are difficult for this group to obtain as literacy is a serious issue amongst many PWID. 
Both SE agencies gave examples of PWID they had worked with who could perform a job well, but could not obtain the relevant qualification as they could not pass the written part of the examination. These jobs included a barista, a rest home support worker and a mechanic apprenticeship. One of the employers interviewed helped their employees to gain a qualification by doing the writing sections of their work for them.

This lack of qualifications is not merely something to put on a resume, as the results have shown that CVs are not an important factor in the employment of PWID. The qualifications are essential in building up the confidence of WPID to begin to search for employment information with a belief that they can perform a job. The confidence derived from achieving educational and vocational qualifications is often denied to PWID through educational structures and the way in which knowledge is tested and demonstrated. This study has shown this to be a major factor influencing the employment information seeking process of PWID.

Both SE agencies had different ideas on how to improve their services. Both SE agencies involved in this project expressed a desire for more promotion of their services. One SE lamented that when they did engage in promotion of their services they had more PWID looking for work responding than employers. The other SE agency said that they really needed a marketing professional to do promotion for their organisation, "which leaves us free to concentrate on what we're there to actually do best." The employer who has a long working relationship with one SE agency believes that "[this agency] needs to be publicised more" and that "more information needs to be given to business."

Printed information was not seen by many as particularly relevant to this group of people and also not a particularly effective mechanism for transmitting information. This is entirely understandable given the issues with literacy that many PWID have, but this perhaps points to a bigger issue within information needs for PWID. One of the PWID who participated in this study did say that, "a DVD about supported employment would be good."

\section{Conclusions}

One of the aims of this research was to assess which mechanisms could be used to meet PWID employment information needs. This research suggests that printed information is not very important, and that tailored or personalised information is the most effective. Although most participants preferred talking in person, some of the PWID preferred using the telephone or email. This highlights the importance of providing information in the users' preferred format.

Moore's idea, that in some cases information alone was not enough to prompt action, was certainly backed up by the results of this research. The findings suggest that one reason for this could be a lack of confidence on the part of the PWID, as they have little expectation of obtaining employment. There was no category to measure previous experience and affective or emotional factors in Moore's model, and these factors came repeatedly to the fore as influences on the employment information needs of PWID. The results of this study suggest that further research into these areas and how they affect the broader information behaviour environment would be illuminating. 
The PWID and the caregiver in this study all had similar questions around employment, which were mainly practical, however the research shows that the major question these groups had around employment centred on what the job actually involved. The SE agencies involved in this project already provide step by step guides and break jobs down into smaller task-based descriptions, although an interesting area for future research would be to gage the effectiveness of these customised job descriptions.

A further aim of this project was to observe which agents initiated the information activity. The research shows that placing participants into seeker/provider/processor groups like Moore's model is inappropriate in this scenario. All participants performed each role depending on the context, and the various groups all had occasions of initiating the information activity.

Trust and authority were important aspects of information for all of the participants in this study, however the methods they used for gaging trust were slightly different. On-going relationships were valued highly, but when this was not the case participants relied on their feelings and experience to judge the information they were processing. 


\section{References}

Andre-Barron, D., Strydom, A. \& Hassiotis, A. (2008) What to tell and how to tell: a qualitative study of information sharing in research for adults with intellectual disability. Journal of Medical Ethics, 34(6), 501-506.

Ashman, A.F., Suttie, J.N. \& Bramley, J. (1995). Employment, retirement and elderly persons with an intellectual disability. Journal of Intellectual Disability Research, 39(2), 107-115.

Association for Supported Employment New Zealand (2011). Frequently asked questions. Retrieved May 6, 2012, from http://www.asenz.org.nz/faq.html

Aveno, A. (1987). A study of leisure activities engaged in by adults who are severely retarded living in different residence and community types. Education and Training in Mental Retardation, 22(2), 121-127.

Baker, L.M. (2004) "The information needs of female Police Officers involved in undercover prostitution work" Information Research, 10(1) Retrieved October 18, 2010, from http://InformationR.net/ir/10-1/paper209.html

Berthoud, R. (2008). Disability employment penalties in Britain. Work, Employment \& Society, 22(1), $129-148$.

Beverley, C. A., Bath, P. A. \& Barber, R. (2007). Can two established information models explain the information seeking behaviour of visually impaired people seeking health and social care information? Journal of Documentation, 63(1), 9-32.

Bryman, A. (2008). Social research methods ( $3^{\text {rd }}$ Ed).Oxford: Oxford University Press.

Case, D. O. (2007). Looking for information: A survey of research on information seeking, needs, and behaviour ( $\left.2^{\text {nd }} \mathrm{ed}\right)$. London: Academic Press.

Charmaz, K. (2006). Constructing grounded theory: A practical guide through qualitative analysis. London: Sage.

Chatman, E.A. (1991). Channels to a larger social world: older women staying in contact with the great society. Library \& Information Science Research, 13, 281-300.

Chatman, E.A. (1999). A theory of life in the round. Journal of the American Society for Information Science, 50(3), 207-217.

Chike, D. (2006). A Study of the information and service needs of adults with intellectual disabilities and how public libraries meet these needs. Retrieved October 18, 2010, from http://dc.lib.unc.edu/u?/s_papers, 840

Cooper, J. and Urquhart, C. (2005). The information needs and information-seeking behaviours of home-care workers and clients receiving home care. Health Information \& Libraries Journal, 22, 107-116.

Corbin, J. \& Strauss, A. (2008). Basics of qualitative research: Techniques and procedures for developing grounded theory ( $\left.3^{\text {rd }} \mathrm{Ed}\right)$. Los Angeles: Sage.

Creswell, J.W. (2007). Qualitative inquiry \& research design: Choosing among five approaches $\left(2^{\text {nd }}\right.$ Ed). Thousand Oaks, CA: Sage.

Cronin, B. (Ed.) (2008). Annual review of information science and technology (v.43). Medford, NJ: Information Today Inc. 
Department of Labour (2011). Employment supports for disabled people. Retrieved December 2, 2012, from http://www.odi.govt.nz/resources/publications/nzds/index.html

Dervin, B. (1999). On studying information seeking methodologically: the implications of connecting metatheory to method. Information Processing and Management, 35, 727-750

Gorman, G.E. and Clayton, P. (Eds.). (2005). Qualitative research for the information professional: A practical handbook ( $2^{\text {nd }}$ ed). London: Facet.

Guba, E. G., \& Lincoln, Y.S. (2005). Paradigmatic controversies, contradictions, and emerging confluences. In N.K. Denzin \& Y.S. Lincoln (Eds.) The SAGE handbook of qualitative research ( $3^{\text {rd }}$ Ed., pp.191-215). Thousand Oaks, CA: Sage.

Hammell, K.W. (2006). Perspectives on disability \& rehabilitation: Contesting assumptions; challenging practice. Edinburgh: Churchill Livingstone.

Harland, J.A. \& Bath, P.A. (2008). Understanding the information behaviours of carers of people with dementia: A critical review of models from information science. Aging \& Mental Health, 12(4), 467-477.

Holliday, A. (2007). Doing and writing qualitative research ( $2^{\text {nd }}$ Ed). London: Sage.

Holmes, J.L. (2008). Patrons with developmental disabilities: A needs assessment survey. New Library World, 109(11/12), 533-545.

Jameson, A. (2005). Disability and employment - review of literature and research. Auckland: Equal Employment Opportunities Trust. Retrieved, May 6, 2012 from http://www.edn.org.nz/resources/research

Kober, R. \& Eggleton, I.R.C. (2005). The effect of different types of employment on quality of life. Journal of Intellectual Disability Research, 49(10), 756-760.

Koulikourdi, A. (2008). Library education and disability issues. Education for Information, 26, 203212.

Lysaght, R., Cobigo, V. \& Hamilton, K. (2012). Inclusion as a focus of employment-related research in intellectual disability from 2000 to 2010: a scoping review. Disability \& Rehabilitation, Early Online, 1-12.

Miles, M.B., \& Huberman, A.M. (1994). Qualitative data analysis: An expanded sourcebook ( $2^{\text {nd }}$ Ed). Thousand Oaks, CA: Sage.

Ministry of Health (2001). The New Zealand Disability Strategy. Retrieved August 22, 2010, from http://www.odi.govt.nz/resources/publications/nzds/index.html

Ministry of Health (2004). Living With Disability in New Zealand. Retrieved May 18, 2012, from http://www.health.govt.nz/publication/living-disability-new-zealand

Moore, M., Beazley, S. \& Maelzer, J. (1998). Researching disability issues. Buckingham: Open University Press.

Moore, N. (2002). A model of social information need. Journal of Information Science, 28(4), 297303.

New Zealand Human Rights Commission. (2011). Tracking equality at work for disabled people. Retrieved May 12, 2012, from http://www.hrc.co.nz/2011/tracking-equality-at-work-fordisabled-people-how-is-new-zealand-going 
New Zealand Parliament. (2007). Disabled Persons Employment Promotion (Repeal and Related Matters) Bill. Retrieved December 4, 2012, from http://www.parliament.nz/en-

NZ/PB/Legislation/Bills/0/0/c/00DBHOH BILL6056 1-Disabled-Persons-Employment-PromotionRepeal-and.htm

Nind, M. and Seale, J. (2009) Concepts of access for people with learning difficulties: Towards a shared understanding, Disability \& Society, 24(3), 273-287.

Norlin, D. (1995). Helping adults with mental retardation satisfy their information needs. In L.L. Walling \& M.M. Irwin (Eds.) Information services for people with developmental disabilities: The library manager's handbook (pp. 181-196). Westport, CT: Greenwood Press.

Okello-Obura, C., Minishi-Majanja, M.K. \& Cloete, L. (2008). Sources of Business Information and Means of Access Used by SMEs in Uganda: The Case of Northern Uganda. Library and Information Science Research Electronic Journal, 18(1), 0-27.

Oliver, M. (2009). Understanding disability: From theory to practice $\left(2^{\text {nd }} \mathrm{ed}\right)$. London: Palgrave Macmillan.

Pickard, A. (2007). Research methods in information. London: Facet.

Statistics New Zealand (2007). 2006 Disability Survey. Retrieved August 22, 2010, from http://www.stats.govt.nz/browse_for_stats/health/disabilities/DisabilitySurvey2006_HOTP06. aspx

Statistics New Zealand (2008). Disability and the labour market in New Zealand in 2006. Retrieved May 12, 2012, from http://www.stats.govt.nz/browse for stats/health/disabilities/disabilityand-the-labour-market-in-nz-2006.aspx

Stone, E., \& Priestley, M. (1996). Parasites, pawns and partners: disability research and the role of non-disabled. The British Journal of Sociology, 47(4), 699-716.

Webber, S. \& Zhu, W. (2007). Employment information needs of Chinese young adults in Sheffield. Journal of Librarianship and Information Science, 39(4), 223-233

Williams, P., Bunning, K., \& Kennedy, H. (2006). ICTs and learning disability: Multidisciplinary perspectives on Project @pple. Aslib Proceedings: New Information Perspectives, 59(1), 97112.

Williamson, K. (1998). Discovered by chance: The role of incidental information acquisition in an ecological model of information use. Library \& Information Science Research, 20(1), 23-40.

Williamson, K. \& Roberts, J. (2010). Developing and sustaining a sense of place: The role of social information. Library \& Information Science Research, 32(4), 281-287.

Williamson, K., Schauder, D. \& Bow, A. (2000). Information seeking by blind and sight impaired citizens: An ecological study. Information Research, 5(4) Retrieved October 17, 2010 from http://informationr.net/ir/5-4/paper79.html 


\section{Appendix}

\section{Information Sheet}

My name is Andrew Henry, a Victoria University of Wellington student, undertaking a research project to complete the Masters of Information Studies degree. This research project is about the employment information needs of people with intellectual disabilities. I will use semi structured interviews to gather data and this project will fill a large gap in the research literature and ultimately help illuminate potential pathways into work opportunities or supported employment.

This research study has been reviewed by the SIM Human Ethics Committee at Victoria University of Wellington and approval has been granted.

You are encouraged to consult with a family member or another independent advocate like a care giver, prior to consenting to involvement in this research project.

Participation will require being interviewed for approximately thirty minutes about employment information, how one finds it, which forms are helpful and who helps with this task. The interview will take place at a location of your choice. The interview will be audio-recorded if permission is granted.

At the conclusion of each interview participants will be read or shown the notes the researcher has made and have the opportunity to confirm and clarify the notes taken. Participants will also have an opportunity to check the transcripts of the interview recording before the data is analysed.

Your name and information you provide will be kept confidential, and the results obtained from the interview will be presented in a form in which participants cannot be identified. The data collected will be stored in a password protected file and access will be restricted to the researcher. The data gathered in the course of carrying out this project will be destroyed two years after the conclusion of the project.

The results of this research project will be deposited with the University Library and available in the Library's online repository.

Feedback and a summary of results will be provided to research participants in a simplified version, written in a non-academic manner.

If you have any further questions regarding this project please contact me via email: henryandr@myvuw.ac.nz. Alternatively you can contact my supervisor Dr Philip Calvert via email: philip.calvert@vuw.ac.nz or by phone 04-463-6629. 